\title{
СРАВНИТЕЛЬНАЯ ХАРАКТЕРИСТИКА КЛАСТЕРОВ И ТЕРРИТОРИАЛЬНО-ПРОИЗВОДСТВЕННЫХ КОМПЛЕКСОВ
}

\section{COMPARATIVE CHARACTERISTICS OF CLUSTERS AND TERRITORIAL PRODUCTION COMPLEXES}

Yu. Mindlin

Summary. The article substantiates the need for changes in the formation of the industrial complex the application of the cluster approach is proposed. The main differences are revealed clusters from other integration models, the directions of advantages of cluster models are defined structures in General and their participants. The article highlights the innovative nature of cluster theory implementation in industrial and other enterprises at the state level and in the regions of the country, the need to strengthen the cluster approach to innovative development in order to increase the competitiveness of goods and services, and update technological support is identified production and so on.

Keywords: cluster, territorial-industrial complex, integration, interconnection, innovation, value added, regional economy.

\author{
Миндлин Юрий Борисович \\ К.э.н., доцент, Московская государственная \\ академия ветеринарной медицины и биотехнологии \\ имени им. К.И. Скрябина \\ mindliny@mail.ru
}

Аннотация. В статье обоснована необходимость проведения изменений в формировании промышленного комплекса региона, предложено применение кластерного подхода. Раскрыты главные отличия кластеров от других интеграционных моделей, определены направления преимуществ кластерных структур в целом и их участников. Освещены инновационность внедрения кластерной теории на промышленных и других предприятиях на государственном уровне и в регионах страны, выявлена потребность усиления кластерного подхода по инновационному развитию для повышения конкурентоспособности товаров и услуг, обновления технологического обеспечения производства и прочее.

Ключевые слова: кластер, территориально-производственный комплекс, интеграция, взаимосвязь, инновации, добавленная стоимость, региональная экономика.

Правительствами многих стран разработана и воплощается государственная политика кластеризации. В то же время региональные органы власти используют кластерный подход для повышения конкурентоспособности своих территорий.

Такой подход базируется на получении дополнительных преимуществ от взаимовыгодного сотрудничества субъектов хозяйствования за счет получения синергетических, сетевых эффектов и снижение уровня трансакционных расходов, что позволяет получить дополнительные конкурентные преимущества на разных этапах социально-экономического развития региона.

Процедура создания кластеров основывается на соответствующих принципах, учитывает конкретные условия и требует определенной последовательности этапов, что предопределяет использования различных мотивационных механизмов участия субъектов хозяйствования в кластерах и является предметом многочисленных научных исследований.

Одной из причин существования длительного развития в экономике России является то, что реформы, которые призваны решить проблемы деформации структуры производства промышленного комплекса, комплекс- 
ного развития отраслей промышленности с учетом региональных особенностей не доводятся до конца. Определяющим фактором на современном этапе трансформации регионально-экономических систем является воссоздание и развитие промышленного комплекса региона.

Под промышленным комплексом следует понимать организованную взаимосвязь отраслей и предприятий региона, а также связь между отраслями (предприятиями) и окружающей средой, между природными, трудовыми ресурсами, производством, населением и его потреблением.

Формирование крупных хозяйственных, промышленных комплексов было начато со времен советской власти. В основе каждого вида комплекса находился производственный процесс. Комплексы представляли собой ведущие звенья в решении задач повышения эффективности производства, что сводилось к получению наибольших положительных результатов при минимальных расходах и наилучшем использовании различных ресурсов. Управление промышленными комплексами предполагает определенное объединение, интеграцию.

Промышленные комплексы в то время были представлены крупными предприятиями, что с одной стороны уменьшало расходы, а с другой - облегчало управление, так как легче реализовывать функции управление относительно небольшого количества крупных предприятий, а чем наоборот.

Пионером в области теоретических исследований по формированию и развитию территориально-производственных комплексов был М.М. Колосовский. Изучение структурного многообразие хозяйственных комплексов привело его к выявлению схожих комбинаций тех или иных производственных процессов, однотипные, хотя и очень разных сочетаний производств в различных отраслях и регионах. На основе этого М.М. Колосовский ввел понятие энергопроизводственные циклы, которые он определил как типичную, устойчивую существующую совокупность производственных процессов, возникающих взаимообусловленно (упорядоченно) вокруг основного процесса для данного вида энергии и сырья [1].

Идея типизации производственных процессов положила начало разработке концепции территориально-производственных комплексов, которые впоследствии широко использовались как форма планирования, так и как форма территориальной организации производства. Таким образом, за прошедшие годы управление территориально-производственными комплексами при помощи планово-административных методов приобрело положительный опыт в установлении и развитии взаимосвязей, комплексном использовании сырья, освоении новых территорий. При этом, промышленные комплексы считались наиболее эффективной с экономической точки зрения формой территориально-производственных комплексов [2].

Процесс формирования промышленных комплексов, как отмечал А.Т. Хрущев, заключается в возникновении их или на базе производства, что уже исторически сложилось, или составлении заново. То есть, промышленный комплекс как историческая категория включает в себя и уже существующие предприятия, и новые, а также характеризуется появлением новых элементов на определенной стадии формирования. Поэтому ученый рассматривал развитие промышленных комплексов как стадийный процесс, структура которого изменяется со временем [2].

Отдельно следует отметить, что обязательным входным параметром работы комплекса наряду с разносторонними ресурсами выступало плановое задание высшего руководства на производство и поставка продукции. Определение сущности планового задания в представленные планового размера готовой продукции комплекса для поставки на определенный период, говорит о его ведущую роль в функционировании и развитии промышленного комплекса. Таким образом, промышленный комплекс не может создаваться стихийно, а только на основе заранее определенной целевой программы. Только в этом случае возможно достижение эффекта при капитальных вложениях и использовании различных видов ресурсов при правильной организации производственных процессов и связей.

Позже появились и другие формы организации производства: производственные объединения, научно-производственные объединения, межотраслевые комплексы, целью которых было преодоление технического отставания, активизация инновационной деятельности.

К изменениям в формировании и управлении промышленным комплексом региона привела структурная трансформация экономики страны. Изменение экономической формации, состоявшейся в начале 90-х годов, привела к разрушению связей в промышленном комплексе, что привело к кризису промышленности в начале существования Российской Федерации, последствия которой полностью не устранены к настоящему времени и усиливаются современным мировым кризисом, экономическими санкциями, а также политической ситуацией в глобальном мире.

Сложившаяся ситуация привела к тому, что предприятия осталась наедине перед проблемами эконо- 
мического реформирование и начали самостоятельно определять направления своего выживания в условиях отсутствия управляющего влияния государства и спроса на продукцию, потери налаженных связей и низкого уровня конкурентоспособности. Таким образом, структура промышленного комплекса оказалась несоответствующей рыночным требованиям вследствие бессистемного его формирования.

В этом контексте уместно поставить научный вопрос о целесообразности создания такого комплекса. Переход к рыночной экономике сопровождался изменением условий владения предприятием. Однако опыт последних лет показал, что такое изменение, во-первых, не приводит автоматически к повышению эффективности или конкурентоспособности предприятий, а во-вторых, сегодня нет реального способа организовать развитие промышленного комплекса. Предприятия, которые входили в промышленный комплекс и имели определенные конкурентные преимущества, меняли владельца и, получая от него разнообразную поддержку, повышали свою конкурентоспособность. Другим предприятиям или удалось преодолеть конкуренцию импорта, или удовлетворить спрос внутреннего рынка, иначе они или уже ликвидированы, или находятся на пути к банкротству. Поэтому, признавая нецелесообразным обновления бывшей отраслевой структуры управления, считаем интегрированные промышленные комплексы, которые образуются на основе объединения предприятий, с использованием преимуществ концентрации, специализации и кооперации, нужными для экономики российского государства.

В контексте процесса глобализации, который сегодня затрагивает экономику не только государства, но и всей области, важно выбрать интеграционную модель, совместный бизнес которой основан на доверии между партнерами. Сегодня существует множество различных типов интеграционных моделей, которые различаются в зависимости от целей сотрудничества, характера экономических отношений между участниками, степени самостоятельности предприятий, входящих в состав объединения, например, в промышленно-финансовые группы, холдинги, корпорации, консорциумы и т.д. Этот тип интеграции обычно решает различные задачи, в том числе: повышение качества управления и эффективного использования ресурсов, снижение издержек и рисков.

На основе анализа указанных выше форм интегрированных структур бизнеса можно выделить следующие преимущества и недостатки их функционирования. К преимуществам крупных компаний и фирм, входящих в такие форм интеграции следует отнести:

- во-первых, обладание ведущей роли в обеспечении научно-технического прогресса, обновлении продукции и технологий вследствие консолидации капиталов;

- во-вторых, возможность широкого использования преимуществ, связанных с внутренней организацией и управлением;

- в-третьих, возможность осуществления большого шага вперед в области диверсификации производства и формировании многоотраслевых моделей, позволяют наилучшим образом реализовать научно-технические, производственные, сбытовые наработки, с целью удовлетворения все более требовательных потребностей рынка.

Но наряду с этим необходимо указать и на существующие недостатки:

- отсутствие конкуренции внутри интегрированных структур;

- недостаток самостоятельности и, как следствие, отсутствие заинтересованности, иждивенческий настрой с стороны некоторых членов интегрированной структуры;

- вероятность застоя на определенных этапах развития;

- слабая регулирующая, контролирующая и поддерживающая роль государства.

Некоторые из перечисленных негативных аспектов деятельности интеграционных структур содержат противоречия относительно цели их создания, а именно: обеспечение относительно равных экономических условий участникам процесса и согласование развития всех технологических звеньев производства конечного продукта. Наличие слабых сторон создают опасность, ведь в случае изменения конъюнктуры рынка, нехватки средств у инвесторов, отсутствия государственной поддержки, промышленные предприятия, входящие в интеграционные схемы, станут неконкурентоспособными на рынке и их экономика вернется к исходным позициям.

На наш взгляд, наиболее эффективной и перспективной интеграционной моделью развития промышленного комплекса в современных условиях является кластерная модель. Кластерная теория базируется на понятии «кластер», что означает пучок, пакет, блок.

Впервые феномен кластера раскрыл А. Маршал более ста лет назад, известной концепцию промышленного кластера сделали работы М. Портера. Кластерный подход также используется в теоретических разработках других ученых, таких как И. Толенадо и Д. Соле, которые использовали понятие «фильеры», которые можно считать прообразами более широкого понятие кластеров. Фильеры определяют одну из причин создания кластеров - необходимость создания технологических связей 


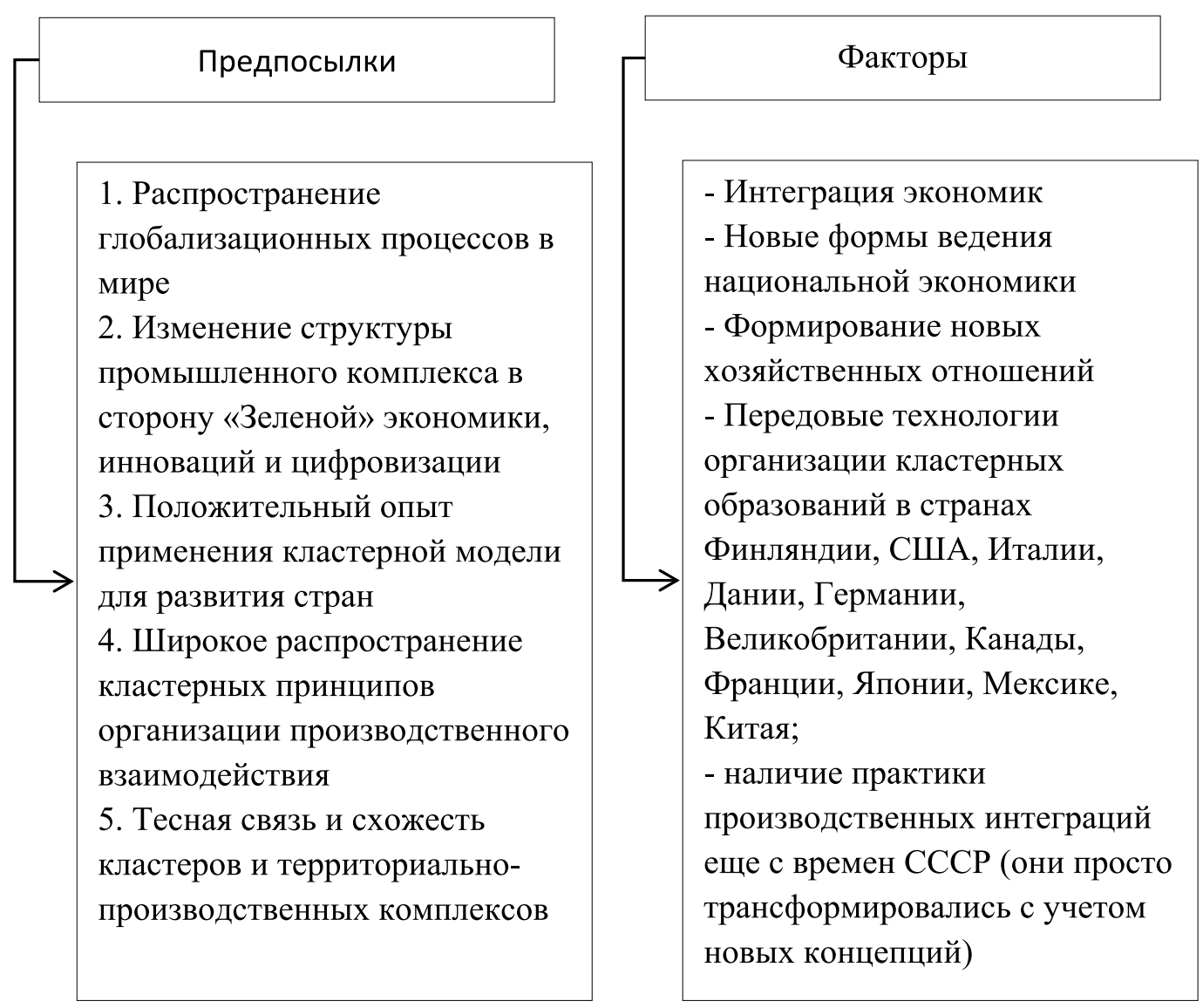

Рис. 1. Предпосылки и факторы популяризации применения кластерной модели относительно становления промышленного комплекса региона Источник: составлено автором на основе $[5,6,7,8,9]$

между отраслями и секторами экономики для реализации потенциальных преимуществ [3].

Шведские исследователи используют понятие «блоки развития», подчеркивая важную связь между способностью одного сектора развиваться и обеспечением прогресса в другом, а также необходимость связи между отраслями для завоевания конкурентных преимуществ.

Однако наиболее кластерная концепция связана с работами Н. Портера, который определяет кластер как «сконцентрированные по географическому признаку группы взаимосвязанных компаний, специализированных поставщиков, поставщиков услуг, фирм в соответствующих отраслях, а также связанные с их деятельностью организаций (например, университетов, агентств по стандартизации, торговых объединений) в определенных областях, конкурирующих, но вместе с тем и проводят совместную работу» [4].

На основе исследований конкурентных возможностей в свыше 100 отраслях в разных странах М. Портер обнаружил, что наиболее конкурентоспособные транснациональные компании обычно не расположены бессистемно по разным странам мира, а концентрируются в пределах одного, или вообще в одном ее регионе.

Понятие кластеризации в экономической системе является относительно новым. Исследования по этому направлению ведутся в последние годы боле активно. Кластерный подход делает экономику более прозрачной и управляемой. Промышленный потенциал сосредотачивается в упорядоченном секторе кластеров. А сами кластеры по мере своего развития становятся центрами притяжения инвестиций, лучших кадровых ресурсов и сопутствующих услуг.

Предлагая применения кластерной модели относительно становления промышленного комплекса региона, следует определить предпосылки и факторы, которые к этому побуждают (рисунок 1).

Прообразами кластеров можно считать территориально-промышленные комплексы (ТПК), которые позво- 
Таблица 1. Разница между кластером и территориально-промышленного комплекса (ТПК)

\begin{tabular}{|c|c|c|}
\hline Параметры сравнения & Кластер & ТПК \\
\hline $\begin{array}{l}\text { Условия существования } \\
\text { (типы экономик) }\end{array}$ & Рыночная & Плановая \\
\hline Генезис & $\begin{array}{l}\text { Пространственное проявление } \\
\text { рыночных сил }\end{array}$ & $\begin{array}{l}\text { Реализация на практике } \\
\text { теоретических разработок } \\
\text { ученых }\end{array}$ \\
\hline Основы производства & $\begin{array}{l}\text { Инновационный подход, гибкая } \\
\text { специализация }\end{array}$ & $\begin{array}{l}\text { Жесткая специализация, } \\
\text { стандартизированность } \\
\text { продукции }\end{array}$ \\
\hline Структура производства & $\begin{array}{l}\text { Централизованная координация по } \\
\text { согласованным направлениям } \\
\text { корпоративно-автономных фирм }\end{array}$ & Централизация \\
\hline $\begin{array}{l}\text { Территориальное } \\
\text { размещение }\end{array}$ & На ограниченной территории & $\begin{array}{l}\text { Внутри региона или } \\
\text { межрегиональное }\end{array}$ \\
\hline $\begin{array}{l}\text { Экономические } \\
\text { показатели }\end{array}$ & $\begin{array}{l}\text { По совокупности отраслей, } \\
\text { которые по отраслям входят в } \\
\text { кластерную систему }\end{array}$ & По отраслям \\
\hline $\begin{array}{l}\text { Государственное } \\
\text { регулирование }\end{array}$ & $\begin{array}{l}\text { Меры по регулированию } \\
\text { кластеров и предприятий }\end{array}$ & $\begin{array}{l}\text { Меры по регулированию } \\
\text { отраслей и предприятий }\end{array}$ \\
\hline $\begin{array}{l}\text { Механизмы } \\
\text { взаимодействия }\end{array}$ & $\begin{array}{l}\text { Формальные наряду с } \\
\text { неформальными (обмен } \\
\text { информацией, технологиями) }\end{array}$ & Формальные \\
\hline Структура и управление & $\begin{array}{l}\text { Сетевая, горизонтальная, } \\
\text { структура «ядро-поставщики»; } \\
\text { малые и средние предприятия по } \\
\text { производству и предоставлению } \\
\text { услуг, вузы, НИИ, органы, } \\
\text { осуществляющие управление } \\
\text { кластерной инициативой }\end{array}$ & $\begin{array}{l}\text { Иерархическая; большие } \\
\text { вертикально-интегрированные } \\
\text { заводы, управление которыми } \\
\text { осуществляется с единого центра } \\
\text { (Министерства, Госплан) }\end{array}$ \\
\hline $\begin{array}{l}\text { Входные параметры } \\
\text { (возбуждающие факторы) }\end{array}$ & Спрос & $\begin{array}{l}\text { Плановое задание на } \\
\text { изготовление и поставку } \\
\text { продукции } \\
\end{array}$ \\
\hline Условия создания & $\begin{array}{l}\text { Путем модернизации старых } \\
\text { существующих индустриальных } \\
\text { модулей }\end{array}$ & С нуля \\
\hline Масштаб & $\begin{array}{l}\text { Одна отрасль или несколько } \\
\text { смежных }\end{array}$ & $\begin{array}{l}\text { Межотраслевой комплекс - } \\
\text { области специализации и } \\
\text { предприятия обслуживающих } \\
\text { отраслей и производств }\end{array}$ \\
\hline Отрасли специализации & $\begin{array}{l}\text { Приоритетные отрасли } \\
\text { промышленности, сферы услуг; } \\
\text { традиционные, ориентированные } \\
\text { на потребителя }\end{array}$ & $\begin{array}{l}\text { Тяжелая промышленность, } \\
\text { ориентирована на производителя }\end{array}$ \\
\hline
\end{tabular}

Источник: составлено автором на основе $[6 ; 9 ; 10 ; 11]$

ляли экономить ресурсы, сокращать объемы капитальных вложений, комплексно и рационально использовать природные ресурсы, получать быструю отдачу вложенных средств. Однако плановая система и отраслевой принцип накладывали жесткие ограничения на их деятельность. Поэтому условия существования (плановая экономика или конкуренция) можно считать одним из главных отличий между кластерами и ТПК [3].
Разница между кластерами и ТПК по основным параметрам сравнения приведена в таблице 1.

Сравнение кластеров и ТПК, приведенное в табл. 1, позволяет отметить, что, во-первых, кластеры являются гибкими и соответствующими современным условиям развития экономики страны образованиями, во-вторых, кластеры устраняют недостатки присущи другим 
интеграционным структурам, поскольку способны обеспечивать сохранение хозяйственной самостоятельности предприятий, способствующих привлечению инвестиций в том числе и для внедрения разнообразных инноваций, позволяют строить новые экономические взаимоотношения между хозяйствующими субъектами и властью и тому подобное.

Применение кластерного подхода существенно расширяет набор традиционных рыночных критериев промышленного развития, что позволяет выявить направления преимуществ новой формы организации промышленных производств.

Среди общих преимуществ кластеров нами разработаны три основные направления с указанием их конкретизации это:

1. повышение производительности предприятий и отраслей: повышение специализации внутри кластера за счет конкуренции; снижение трансакционных и накладных расходов, в том числе и за счет экономии масштаба и т.п.;

2. расширение возможностей инновационного и производственного роста: создание каналов для эффективного сотрудничества новых потен- циальных инновационных ресурсов, мониторинг и прогнозирование технологических инноваций и т.п.;

3. стимулирование и облегчение формирования новых предприятий и новых видов деятельности: поддержка появления новых участников; укрепление разного рода неформальных связей, в том числе и социальных, для появления новых идей, предприятий, видов деятельности и т.п.

Итак, проведенный анализ зарождения и развития промышленного комплекса региона в различные периоды его функционирования позволяет во-первых, очертить главные трудности, которые тормозят процесс роста промышленности региона; во-вторых, обосновать целесообразность применения новых подходов к его формированию. Решение вопроса целесообразности таких комплексов, по нашему мнению, заключается в применении кластерного подхода как наиболее эффективной и прогрессивной интеграционной модели, которая позволяет: сохранить хозяйственную самостоятельность предприятий; привлечь больше инвестиций; создать распространение инноваций; построить новые экономические взаимоотношения между хозяйствующими субъектами и властью.

\section{ЛИТЕРАТУРА}

1. Колосовский Н. Н. Теория экономического районирования. - М.: Мыслью - 1969. - 334 с.

2. Хрущев А. Т. География промышленности СССР: [учебн. для геогр. спец. вузов]. — М.: Высш. школа.—1990.— 223 с.

3. Ленчук Е. Б., Власкин Г. А. Кластерный подход в системе инновационного развития России // Проблемы прогнозирования. 2010. № 6. С. 45-57.

4. Porter M. E. The Competitive Advantage of Nations // Harvard Business Review. 1990. March-April. P. 73-93

5. Егоров А. В. Кластер.— М.: АВТОР, 2018. - 273 с.

6. Кластеры идут // Компаньон.— 2005.— № 16 (428) 22-28 апреля.—С. 60-63.

7. Жамбю М. Иерархический кластер-анализ и соответствия.— М.: Финансы и статистика, 2017. - 344 c.

8. К Кластеры конкурентоспособности Финляндии // Вестник Санкт-Петербургского университета. — 2004. — Сер. 5. Вып. 1 (№ 5). — C. 71-78.

9. Азоев, Г. Л. Инновационные кластеры наноиндустрии.- М.: Бином. Лаборатория знаний, 2015. -40 c.

10. Громыко Ю. В. Что такое кластеры и как их создавать // Восток: альманах. - 2007. — Вып. 1(42). - 10 с.

11. Бочкова Е., Кузнецова Е. Институт кластера в системе территориального разделения труда России.— M.: LAP Lambert Academic Publishing, 2013.— 104 c. 